\title{
Recent advances in convex probe endobronchial ultrasound: a narrative review
}

\author{
Jian $\mathrm{Wu}^{1} \wedge$, Cen $\mathrm{Wu}^{2} \wedge$, Chuming $\mathrm{Zhou}^{2} \wedge$, Wei Zheng ${ }^{2} \wedge$, Peng $\mathrm{Li}^{2} \wedge$ \\ ${ }^{1}$ Department of Anesthesiology, Shengjing Hospital of China Medical University, Shenyang, China; ${ }^{2}$ Department of Pulmonary and Critical Care \\ Medicine, Shengjing Hospital of China Medical University, Shenyang, China \\ Contributions: (I) Conception and design: P Li, C Wu, W Zheng; (II) Administrative support: None; (III) Provision of study materials or patients: \\ None; (IV) Collection and assembly of data: P Li, J Wu; (V) Data analysis and interpretation: None; (VI) Manuscript writing: All authors; (VII) Final \\ approval of manuscript: All authors. \\ Correspondence to: Peng Li, MD. Department of Pulmonary and Critical Care Medicine, Shengjing Hospital of China Medical University, No. 36 \\ Sanhao Street, Heping District, Shenyang 110004, China. lipengcmu@163.com.
}

\begin{abstract}
Convex probe endobronchial ultrasound (CP-EBUS) has been widely used in the lymph node staging and restaging of lung tumors and the diagnosis of mediastinal diseases. Recent years have seen continuous progress in this technology. For diagnosis, elastography technology can preliminarily distinguish between benign and malignant lesions, so that reduce the number of punctures. CP-EBUS can also be used as an endoscopic ultrasound (EUS) to guide needle aspirations of liver lesions, retroperitoneal lymph nodes and left adrenal gland (LAG) lesions sometimes. Some advances help diagnosing more accurately and effectively, such as the intranodal forceps biopsy (IFB), the new type of $22 \mathrm{G}$ needle, the rapid on-site evaluation (ROSE) and the cancer gene methylation, etc. In addition, special advances are being made in diagnosis using artificial intelligence (AI). For treatment, CP-EBUS has yielded novel research results when applied to transbronchial needle injection (TBNI) and radioactive seed implantation in clinical cases, and blocking of the cardiac plexus in animal studies. The next-generation CP-EBUS is also ready for use in the clinic and the technology will be improving continuously. Through this review, we hope to educate clinicians on the latest uses of CP-EBUS and open up further research ideas for readers interested in this technology.
\end{abstract}

Keywords: Endobronchial ultrasound (EBUS); elastography; transbronchial needle aspiration (TBNA); intranodal forceps biopsy (IFB); rapid on-site evaluation (ROSE); transbronchial needle injection (TBNI)

Submitted Dec 28, 2020. Accepted for publication Feb 10, 2021.

doi: $10.21037 / \mathrm{atm}-21-225$

View this article at: http://dx.doi.org/10.21037/atm-21-225

\section{Introduction}

Convex probe endobronchial ultrasound (CP-EBUS) has been applied clinically for nearly 30 years. Through the unremitting efforts of clinicians, this technology is now mature and safe, enabling a clear diagnosis for a large number of patients. Endobronchial ultrasound-guided transbronchial needle aspiration (EBUS-TBNA) is the most important application of EBUS. It can be used for accurate lymph node staging and restaging of lung tumors $(1,2)$, as well as the diagnosis of several mediastinal diseases. Patients usually undergo this procedure under sedation only (3). Although the technology is mature, much space remains for exploring applications of CP-EBUS, and its indications are constantly expanding. This review focuses on the two aspects of diagnosis and treatment, summarizing the latest progress in the basic and clinical research fields of CP-

^ ORCID: Jian Wu, 0000-0002-3439-7435; Cen Wu, 0000-0003-0456-9125; Chuming Zhou, 0000-0001-9472-1914; Wei Zheng, 00000002-7522-2914; Peng Li, 0000-0002-6060-0089. 
EBUS, and opening up further research ideas for readers interested in this technology.

We present the following article in accordance with the Narrative Review reporting checklist (available at http:// dx.doi.org/10.21037/atm-21-225).

\section{Diagnosis}

\section{Elastography}

Elastography is a type of ultrasound imaging which displays different colors under ultrasound according to the degree of deformation of the mediastinal lymph nodes or lesions after compression (4). Green and red (Type 1) represent soft masses and often suggest benign lesions, blue (Type 3) represents hard masses and often suggests malignancy, while blue-green mixed (Type 2) cannot be judged. Currently, EBUS is equipped with this function, and this technology has been an active area of research. In 2019, research on elastography still focused on judging lesions. Two studies found that the consistency rates of Type 3 lymph nodes with pathology were $80.7 \%$ (5) and $73 \%$ (6), and results having no significant correlation with the maximum standardized uptake value of positron emission tomography-computed tomography (PET-CT) images (5). From the above findings, elastography has been shown to help distinguish benign from malignant growths, but cannot replace needle aspiration biopsy. For now, we can only reduce the number of punctures (7). In practice, we should attach great importance to Type 3 lymph nodes and try to obtain specimens. For lymph nodes of the same stage, puncture should be performed from Type 1 to Type 3 in order to avoid artificial detection errors or implantation metastasis.

\section{Endoscopic ultrasound with bronchoscope (EUS-B)}

Ultrasound bronchoscopy, as the name implies, is performed mainly in the airways, but can be performed by a pulmonologist, thoracic surgeon, or endoscopist. Therefore, unlike digestive endoscopy, there is no technical obstacle to its application, and the length of the endoscopy body may be the only bottleneck. It is routine practice for doctors to extend the ultrasound bronchoscope into the esophagus and TBNA to the mediastinal lymph nodes in groups 8 and 9 . However, the use of CP-EBUS to detect and puncture liver lesions (8), retroperitoneal lymph nodes (8), and left adrenal gland (LAG) lesions (9) are new applications. A study of the LAG showed that, of the 274 patients studied, 78 had
LAG abnormalities detected by EUS-B and underwent fine needle aspiration (FNA), after which 9 cases (11.5\%) of malignant lesions were confirmed. Based on these findings, the authors suggested that LAG examinations should be a routine part of EBUS inspections (9). Here, we remind readers that if EBUS-TBNA is used for purposes beyond the $\mathrm{N}$ staging of mediastinal lymph nodes in lung cancer, it is necessary to replace the needle before puncture of a new lesion in order to avoid the risk of implantation metastasis.

\section{TBNA and intranodal forceps biopsy (IFB)}

As for the needle, the models available at present are mainly $25 \mathrm{G}, 22 \mathrm{G}$, and $19 \mathrm{G}$. In terms of sample quantity, $19 \mathrm{G}$ is better than $22 \mathrm{G}$, with equivalent safety (10). The $22 \mathrm{G}$ and the $25 \mathrm{G}$ needles show no significant difference in diagnostic accuracy (11). Compared with the standard needle, the new $22 \mathrm{G}$ needle with a groove (ProCore ${ }^{\circledR}$ ) has improved diagnostic ability (12-14). A comparative study of IFB and TBNA showed that TBNA performed better than IFB for diagnosing malignant diseases, however, IFB was better at diagnosing nonmalignant diseases (15). This result reminds us that patients may benefit from the use of IFB when they are diagnosed with a benign disease. In terms of the number of punctures, each lesion should be punctured at least three times in order to obtain a higher diagnostic rate and provide material for further mutation analysis (16). Several studies have also confirmed that obtaining more samples by EBUSTBNA can meet the needs of further mutation analysis after diagnostic examinations have been completed (17-19).

\section{Specimen processing}

Although EBUS-TBNA has been shown to provide enough specimens, compared with other methods (such as mediastinoscopy, percutaneous lung biopsy, or surgery), the specimens obtained by needle aspiration biopsy can be scarce, and therefore, precious. Sometimes, the needle may yield few specimens, however, the suction syringe may collect some material. This collected material has been found to have a high agreement with the final diagnosis, suggesting that the collected material should be mixed with the needle aspiration specimens (20). After obtaining the core tissue, normal saline is flushed through the needle to obtain a rinse fluid sample. In 331 patients with benign lesions, 42 (12.7\%) were later diagnosed with tuberculous lymphadenitis using rinse fluid samples (21). This result suggests that using existing specimens to improve the 
diagnosis rate of benign diseases represents an important research direction for CP-EBUS.

The clinical value of rapid on-site evaluation (ROSE) for EBUS-TBNA has also been recognized. Studies have confirmed that ROSE can be accomplished by trained nonpathologists, such as pulmonologists (22), and perhaps even by artificial intelligence (AI) in the future (23). When ROSE cannot be implemented, macroscopic on-site evaluation (MOSE) using filter paper can also evaluate the specimen quality and improve the accuracy of diagnosis (24). Normally, a TBNA specimen is processed by a hospital pathologist and a final diagnosis is made. If the preoperative evaluation or ROSE suggests that the disease is malignant, but the final pathology result is negative, the clinician faces a dilemma. Neither passive regular follow-up nor active secondary EBUS-TBNA seem to be the best choice, and further examination of the obtained specimens might be the most cost-effective option. A retrospective study of 887 patients with EBUS-TBNA was carried out, and 44 patients had negative results. When pancytokeratin immunohistochemistry was performed on these negative specimens, 3 patients $(6.8 \%)$ were found to have cytokeratin-positive micrometastasis (25). This situation raises an interesting question. For patients with clinically suspected tumors, should hematoxylin and eosin negative specimens be further evaluated by immunohistochemistry? At present, most pathology departments will not do so. In recent years, the detection of lung cancer gene methylation has been on the rise. Studies show that this method can help distinguish between benign and malignant pathological specimens (26). The combination of SHOX2 and RASSF1A has been commercialized in China, and this method provides a powerful qualitative tool for the analysis of negative specimens.

\section{$A I$}

The use of AI-assisted ROSE has been proposed. In fact, AI has rapidly integrated into all aspects of the medical field. One common application involves finding abnormalities accurately through deep learning of a large number of images. CP-EBUS also obtains images, so can it be combined with AI? Some researchers have used a large number of radial probe EBUS images to perform deep learning analysis. In one such study, the accuracy of diagnosis was $85.4 \%$, the sensitivity was $87.0 \%$, and the specificity was $82.1 \%$, which shows the strong potential of this application (27). The combination of CP-EBUS and AI is believed to soon become a research topic of great interest.

\section{Treatment}

CP-EBUS itself cannot treat disease directly, but through its guidance, with the aid of a needle and other tools, many diseases can be treated. Transbronchial needle injection (TBNI) is the most commonly used method. Cisplatin injection through TBNI has been used to treat mediastinal neoplasms. A recent study showed that optimizing the number and location of EBUS-TBNI sites significantly reduced the cisplatin dose required for the effective treatment of lung cancer (28). CP-EBUS can also be used to guide the placement of fiducial markers, which facilitates precise positioning for radiotherapy. The use of autologous blood instead of commercial foreign materials to block the needle reduces the cost to radiotherapy patients and the possibility of being injured by foreign bodies (29). Through CP-EBUS, iodine-125 radioactive seeds can be implanted for local radiotherapy. Among the 40 patients treated in a seed implantation study, 30 (75\%) had complete remission or partial remission at 6 months with no deaths, suggesting that the treatment may have good efficacy and safety (30).

At present, CP-EBUS is mainly used for mediastinaloccupying lesions. In addition to the treatments discussed, other uses include aspiration of mediastinal cysts and abscesses $(31,32)$. Research on cardiovascular disease is mainly limited to the diagnosis of pulmonary embolism $(33,34)$ and rare pulmonary vascular tumors $(35,36)$, and has yet to enter the treatment stage. According to the anatomic position of the cardiac plexus, researchers injected lidocaine into the aortopulmonary window under the guidance of CP-EBUS, which effectively blocked the cardiac plexus (37). Although this study was in an animal model, it paves the way for another future application of CP-EBUS. CP-EBUS may be used in the future as a high-precision guide for puncture and drug injection to treat refractory arrhythmias, refractory pain, and other conditions.

\section{Summary}

The above describes the recent academic progress in the field of CP-EBUS diagnosis and treatment. In addition, clinical research has also confirmed the application of CPEBUS in pediatrics (38-42). The next-generation CPEBUS (BF-Y0063; Olympus Corporation, Tokyo, Japan) is also ready for use in the clinic, with a smaller probe and more flexibility (43). With clinicians and equipment 
manufacturers working together, CP-EBUS technology will improve, and ultrasonic robots may even be developed (44), providing even more benefits to patients.

\section{Acknowledgments}

Funding: None.

\section{Footnote}

Reporting Checklist: The authors have completed the Narrative Review reporting checklist. Available at http:// dx.doi.org/10.21037/atm-21-225

Conflicts of Interest: All authors have completed the ICMJE uniform disclosure form (available at http://dx.doi. org/10.21037/atm-21-225). The authors have no conflicts of interest to declare.

Etbical Statement: The authors are accountable for all aspects of the work in ensuring that questions related to the accuracy or integrity of any part of the work are appropriately investigated and resolved.

Open Access Statement: This is an Open Access article distributed in accordance with the Creative Commons Attribution-NonCommercial-NoDerivs 4.0 International License (CC BY-NC-ND 4.0), which permits the noncommercial replication and distribution of the article with the strict proviso that no changes or edits are made and the original work is properly cited (including links to both the formal publication through the relevant DOI and the license). See: https://creativecommons.org/licenses/by-nc-nd/4.0/.

\section{References}

1. Jiang L, Huang W, Liu J, et al. Endosonography with lymph node sampling for restaging the mediastinum in lung cancer: A systematic review and pooled data analysis. J Thorac Cardiovasc Surg 2020;159:1099-108.e5.

2. Cetinkaya E, Usluer O, Y1lmaz A, et al. Is endobronchial ultrasound-guided transbronchial needle aspiration an effective diagnostic procedure in restaging of non-small cell lung cancer patients? Endosc Ultrasound 2017;6:162-7.

3. Cornelissen CG, Dapper J, Dreher M, et al. Endobronchial ultrasound-guided transbronchial needle aspiration under general anesthesia versus bronchoscopistdirected deep sedation: A retrospective analysis. Endosc
Ultrasound 2019;8:204-8.

4. Dietrich CF, Jenssen C, Herth FJ. Endobronchial ultrasound elastography. Endosc Ultrasound 2016;5:233-8.

5. Fournier C, Dhalluin X, Wallyn F, et al. Performance of Endobronchial Ultrasound Elastography in the Differentiation of Malignant and Benign Mediastinal Lymph Nodes: Results in Real-life Practice. J Bronchology Interv Pulmonol 2019;26:193-8.

6. Hernández Roca M, Pérez Pallarés J, Prieto Merino D, et al. Diagnostic Value of Elastography and Endobronchial Ultrasound in the Study of Hilar and Mediastinal Lymph Nodes. J Bronchology Interv Pulmonol 2019;26:184-92.

7. Zarogoulidis P, Sapalidis K, Fyntanidou V, et al. Evaluating the use of elastography in endobronchial ultrasound technique as a diagnostic approach for mesothorax lymphadenopathy. Expert Rev Respir Med 2019;13:1153-9.

8. Christiansen IS, Bodtger U, Naur TMH, et al. EUS-BFNA for Diagnosing Liver and Celiac Metastases in Lung Cancer Patients. Respiration 2019;98:428-33.

9. Darwiche K, Becker J, Winantea J, et al. Integration of Bronchoscopic Transesophageal Ultrasound Examination of the Left Adrenal Gland into Routine Lung Cancer Staging Workup: A Prospective Trial. Respiration 2020;99:43-9.

10. Wolters C, Darwiche K, Franzen D, et al. A Prospective, Randomized Trial for the Comparison of 19-G and 22-G Endobronchial Ultrasound-Guided Transbronchial Aspiration Needles; Introducing a Novel End Point of Sample Weight Corrected for Blood Content. Clin Lung Cancer 2019;20:e265-73.

11. Di Felice C, Young B, Matta M. Comparison of specimen adequacy and diagnostic accuracy of a 25 -gauge and 22-gauge needle in endobronchial ultrasoundguided transbronchial needle aspiration. J Thorac Dis 2019;11:3643-9.

12. McCracken DJ, Bailey M, McDermott MT, et al. A retrospective analysis comparing the use of ProCore ${ }^{\circledR}$ with standard fine needle aspiration in endobronchial ultrasound-guided transbronchial needle aspiration (EBUS-TBNA). Ir J Med Sci 2019;188:85-8.

13. Ang TL, Li JW, Kwek AB, et al. The difference in histological yield between 19G EUS-FNA and EUS-fineneedle biopsy needles. Endosc Ultrasound 2019;8:255-60.

14. Fabbri C, Fornelli A, Fuccio L, et al. High diagnostic adequacy and accuracy of the new $20 \mathrm{G}$ procore needle for EUS-guided tissue acquisition: Results of a large multicentre retrospective study. Endosc Ultrasound 2019;8:261-8. 
15. Labarca G, Sierra-Ruiz M, Kheir F, et al. Diagnostic Accuracy of Endobronchial Ultrasound Transbronchial Needle Aspiration in Lymphoma. A Systematic Review and Meta-Analysis. Ann Am Thorac Soc 2019;16:1432-9.

16. Zhang Y, Xie F, Mao X, et al. Determining factors of endobronchial ultrasound-guided transbronchial needle aspiration specimens for lung cancer subtyping and molecular testing. Endosc Ultrasound 2019;8:404-11.

17. Kage H, Kohsaka S, Shinozaki-Ushiku A, et al. Small lung tumor biopsy samples are feasible for high quality targeted next generation sequencing. Cancer Sci 2019;110:2652-7.

18. Smith A, Wang H, Zerbo A, et al. Programmed Death Ligand 1 Testing of Endobronchial Ultrasound-guided Transbronchial Needle Aspiration Samples Acquired For the Diagnosis and Staging of Non-Small Cell Lung Cancer. J Bronchology Interv Pulmonol 2020;27:50-7.

19. Chaddha U, Hogarth DK, Murgu S. The role of endobronchial ultrasound transbronchial needle aspiration for programmed death ligand 1 testing and next generation sequencing in advanced non-small cell lung cancer. Ann Transl Med 2019;7:351.

20. Jagan N, Landeen CA, Moore DR, et al. Waste not, want not: diagnostic material found in suction syringe aspirate during endobronchial ultrasound guided transbronchial needle aspiration. J Thorac Dis 2019;11:3270-5.

21. Ko RE, Jeong BH, Chon HR, et al. Clinical usefulness of routine AFB culture and MTB PCR of EBUS-TBNA needle rinse fluid. Respirology 2019;24:667-74.

22. Wan T, Li Y, Hu Q, et al. Diagnostic value of rapid on-site evaluation during endobronchial ultrasound with a guide sheath for peripheral pulmonary lesions. Cytopathology 2020;31:16-21.

23. Yang F, Liu E, Sun S. Rapid on-site evaluation (ROSE) with EUS-FNA: The ROSE looks beautiful. Endosc Ultrasound 2019;8:283-7.

24. Oh D, Seo DW, Hong SM, et al. The impact of macroscopic on-site evaluation using filter paper in EUS-guided fine-needle biopsy. Endosc Ultrasound 2019;8:342-7.

25. Belanger AR, Hollyfield J, Yacovone G, et al. Incidence and clinical relevance of non-small cell lung cancer lymph node micro-metastasis detected by staging endobronchial ultrasound-guided transbronchial needle aspiration. J Thorac Dis 2019;11:3650-8.

26. Leiro V, De Chiara L, Rodríguez-Girondo M, et al. Methylation Assessment for the Prediction of Malignancy in Mediastinal Adenopathies Obtained by Endobronchial Ultrasound-Guided Transbronchial Needle Aspiration in
Patients with Lung Cancer. Cancers (Basel) 2019;11:1408.

27. Chen CH, Lee YW, Huang YS, et al. Computer-aided diagnosis of endobronchial ultrasound images using convolutional neural network. Comput Methods Programs Biomed 2019;177:175-82.

28. Mori V, Roy GS, Bates JHT, et al. Cisplatin Pharmacodynamics Following Endobronchial UltrasoundGuided Transbronchial Needle Injection into Lung Tumors. Sci Rep 2019;9:6819.

29. Garner JL, Meireles I, Kemp SV, et al. Fiducial marker implantation using convex probe EBUS and autologous blood. BMJ Case Rep 2019;12:e228773.

30. Xu T, Peng WD, Gu X, et al. Endobronchial UltrasoundGuided Iodine-125 Radioactive Seed Implantation as a Novel Therapy for Mediastinal Tumors. Cancer Biother Radiopharm 2019;34:547-50.

31. Maturu VN, Dhooria S, Agarwal R. Efficacy and Safety of Transbronchial Needle Aspiration in Diagnosis and Treatment of Mediastinal Bronchogenic Cysts: Systematic Review of Case Reports. J Bronchology Interv Pulmonol 2015;22:195-203.

32. Tian L, Krimsky WS, Wu Q, et al. Risks and benefits in treatment of mediastinal abscess by endobronchial ultrasound-guided transbronchial needle aspiration. Clin Respir J 2017;11:448-52.

33. Dhillon SS, Harris K. Endobronchial ultrasound for the detection of chronic pulmonary artery thrombus. Endosc Ultrasound 2016;5:272-3.

34. Li P, Wu C, Zheng W, et al. Pathway and application value of exploration of the pulmonary artery by endobronchial ultrasound. J Thorac Dis 2017;9:5345-51.

35. Harris K, Modi K, Kumar A, et al. Endobronchial ultrasound-guided transbronchial needle aspiration of pulmonary artery tumors: A systematic review (with video). Endosc Ultrasound 2015;4:191-7.

36. Li P, Zheng W, Zhao L. Convex probe endobronchial ultrasound: applications beyond conventional indications. J Thorac Dis 2015;7:E289-97.

37. Assis FR, Yu DH, Zhou X, et al. Minimally invasive transtracheal cardiac plexus block for sympathetic neuromodulation. Heart Rhythm 2019;16:117-24.

38. Qin C, Wei B, Ma Z. Endobronchial ultrasound: Echoing in the field of pediatrics. Endosc Ultrasound 2018;7:371-5.

39. Shanthikumar S, Massie J, Ranganathan S, et al. Utility of Endobronchial Ultrasound in Assessment of Intrathoracic Lesions in Paediatric Patients. Respiration 2019;98:340-6.

40. Fuso L, Varone F, Magnini D, et al. New Frontiers in Ultrasonography of the Mediastinum: Pediatric EBUS- 
TBNA. Respir Care 2019;64:358-9.

41. Gulla KM, Gunathilaka G, Jat KR, et al. Utility and safety of endobronchial ultrasound-guided transbronchial needle aspiration and endoscopic ultrasound with an echobronchoscope-guided fine needle aspiration in children with mediastinal pathology. Pediatr Pulmonol 2019;54:881-5.

42. Bouso JM, Yendur O, Hysinger E, et al. EBUS Guided Biopsy is Feasible, Safe, and Improves Diagnostic Yields in Immunocompromised Children. Am J Respir Crit Care Med 2020;201:384-6.

43. Fujino K, Ujiie H, Kinoshita T, et al. First Evaluation of the Next-Generation Endobronchial Ultrasound System in Preclinical Models. Ann Thorac Surg 2019;107:1464-71.

44. Guo J, Li H, Chen Y, et al. Robotic ultrasound and ultrasonic robot. Endosc Ultrasound 2019;8:1-2.

(English Language Editor: C. Betlazar-Maseh)
Cite this article as: $\mathrm{Wu} \mathrm{J}, \mathrm{Wu} \mathrm{C}$, Zhou $\mathrm{C}$, Zheng W, Li P. Recent advances in convex probe endobronchial ultrasound: a narrative review. Ann Transl Med 2021;9(5):419. doi: 10.21037/ atm-21-225 